\title{
Cultural Change for Aspiration Adaptation: Role of NGO's in Rural Bangladesh
}

\author{
Abu Hena Reza Hasan \\ Department of International Business, University of Dhaka \\ Dhaka 1000, Bangladesh \\ abuhasan@univdhaka.edu
}

\begin{abstract}
The cultural values in a society affects aspiration window and aspiration adaptation of people belong to that society. The socially transmitted behavioural pattern, the culture, plays important role towards socio-economic changes in the households and country. The changes in culture may be autonomous of exogenously affected. The social organisations like NGOs may act as external agents of changes in culture of a society to initiate aspiration adaptation among the poor. This paper evaluates ability of NGOs to change traditional values to employment, education, healthcare, and women empowerment. Analysing data from a household field survey in rural area of Bangladesh it has been observed that NGOs have ability to change traditional cultural values slowly and partially. The NGOs are successful to reduce poverty and to change approach to healthcare of traditional society. They could not show enough success in raising educational level. NGOs achieved some successes in women empowerment by motivating educated women to work more in earned activities, and by reducing deprivation of women in healthcare. In general, the paper observed that NGOs are able to change culture of a society that may enhance capability of people and may ensure socio-economic development of households in rural areas of Bangladesh to some extent. Hence, NGOs are agents of cultural change in society to create new aspiration windows and aspiration adaptation.
\end{abstract}

Keywords: Culture; Empowerment of women; rural development; Social mobilization; NGOs.

\section{Introduction}

Aspiration is the cognitive world of an individual that determines that shapes level of achievements of an individual. An aspiration gap develops when desired state of aspiration is different from existing state of aspiration (Ray, 2006). The existence of aspiration gap is the indication that aspiration level of people could be modified through some stimulus. A modification of aspiration by changing circumstances is known as aspiration adaptation (Selten, 1998). The poor in the society lack aspirational resources to contest and to change their state of poverty (Ray, 2006). Aspirational resources may be psychological, institutional and capability enhancement. The poor need motivation to aspire, institutional supports in their operations and skill and ability in them to perform. Poor people of rural area in Bangladesh accepted their present state as their fate and often lack appropriate aspiration to change this fate. To reduce poverty and bring them out of destitution, many Non Government Organisations (NGO) are working in rural areas of Bangladesh. They are encouraging aspiration adaptation through changes in culture in rural society. The objective of this paper is to evaluate success of some NGOs in rural Bangladesh in aspiration adaptation for improving standard of living of the poor.

\section{Literature Review}

Culture is the way of life that influences value system of a society and determines society's attitude toward health, education, job pattern, wealth distribution in households, and status of women in society. Tylor (1974) writing from the perspective of social anthropology described culture as "culture or civilisation, taken in its wide ethnographic sense, is that complex whole which includes knowledge, belief, art, morals, law, custom, and any other capabilities and habits acquired by man as a member of society". The United Nations Economic, Social and Cultural Organisation UNESCO (2002) defines culture as "... culture should be regarded as the set of distinctive spiritual, material, intellectual and emotional features of society or a social group, and that it encompasses, in addition to art and literature, lifestyles, ways of living together, value systems, traditions and beliefs". Hence, culture is socially transmitted behaviour patterns of individuals who belong to a society.

The culture affect aspiration window of people. Amartya Sen's capability approach states that neither resource nor utility can adequately represent welfare and deprivation, rather human functioning, and 
capability to achieve functioning determine welfare and growth of individuals (Clark, 2005). Functioning is an achievement of a person that shows what a person is, or can be, and does, or can do (Sen, 1985). Achieving functioning depends on a range of personal and social factors like body size, gender, health status and access to healthcare, knowledge and education, social class system etc. Capability is ability of a person to achieve a given functioning (Sen, 1993; Saith, 2001; Sen, 2005). However, person's desire to achieve capabilities for functioning is influenced by what he or she would value to achieve in being and doing (Derobert, Luchini \& Teschl, 2003). It means human nature and functioning are linked. Human nature is often influenced by existing culture of the society. So, the culture influences its members' capability and functioning significantly and ultimately determine aspiration window.

An insight into the culture of a society is essential for aspiration adaptation. The culture is a key determinant of success and failure of social and economic processes. Failure of aid programmes in Sudan during famine of 1998 was originated from inability of foreign aid workers to understand local culture regarding group belongingness and resource distribution mechanism (Rao \& Walton, 2004). What the foreign aid workers assumed as food hoarding and corruption was actually a process of food redistribution mechanism in southern Sudan. Acceptance of cultural norms of sex workers in Sonagachi of Kolkata within the process of the HIV-AIDS intervention programme made it highly successful (Rao \& Walton, 2004). In addition to other factors, culture played critical role behind the economic success of South Koreans. Positive attitude of Korean culture to thrift, investment, hard work, education, organisation and discipline enabled this nation to utilise available political and economic opportunities for economic growth (Harrison \& Huntington, 2000). There are plenty of evidences against the general assumption of economists that human used to have same behaviour pattern for maximisation of own utility, rather the fact is, cultural influences can make major changes in behaviour regarding ethics, risks, conduct and entrepreneurial initiatives (Sen, 2004). Social and gender relations in a society are also fixed by cultural norms (Obaid, 2005). Through understanding of cultural norms and values may facilitate aspiration process without creating social conflicts.

A modification in aspiration window and aspiration adaptation is possible as the culture is not static. Some organised efforts may change cultural values in a society. Cultures are not isolated and modify themselves through interaction with each other (Goody, 1996; Sen, 2004; Throsby, 2001). Institutions' generated morals may change cultural values in a society (North, 1990; Sen, 2004). Development takes place within cultural context and people may recreate cultures by reshaping values, norms and expressions (Obaid, 2005). Hence, culture goes through evolution and organisations may play important role as a catalyst. Institutional interventions may create new aspiration window for the poor and help them coming out of poverty. The rural Bangladesh needs aspiration adaptation for poverty reduction. Bangladesh is a poor country whose rural areas are characterised by low level of education and literacy rate, especially among women. The common culture in rural society is low interest in modern healthcare, separation of women from earned employments, uneven distribution wealth, and benefits between male and female within households and poverty. The poor need new aspiration window for acquiring capabilities to come out of destitution.

The non-governmental organisations (NGOs) are engaged in rural Bangladesh to initiate aspiration adaptation. These organisations are working to change traditional value systems regarding right of women, attitude towards education and healthcare and other issues to ensure social and economic development. The NGOs have critical role behind Bangladesh's achievements in poverty reduction and human development over the past three decades. Most of the leading NGOs in Bangladesh are progressive, women friendly and development oriented. The development NGOs undertake wide range of activities, including microfinance, health and education services, social safety net programs, agricultural extension, social forestry and environmental protection, safe water and sanitation, disaster management and relief, and legal and human rights education (Zohir, 2004). A survey on Bangladeshi NGOs shows that 93 percent of them are involved in awareness-raising activities, usually relating to sanitation, health, and social issues (World Bank, 2006). They are social motivators and change agents. The NGOs in Bangladesh used to provide services to their members. Membership is usually voluntary and people become members of NGOs after being motivated by awareness campaigns by the organisations. Hence, it is the assumption that NGOs are successful in aspiration adaptation among their members by altering aspiration windows of people. 


\section{Theoretical Framework of Aspiration Adaptation}

This paper assumes that NGOs in Bangladesh are change agents for socio-economic development of rural poor. They have abilities to change cultural values of people and thereby can establish modified culture or new aspiration window necessary to reject backward values and customs. The following is a theoretical explanation how aspiration may change and aspiration adaptation is possible in society through institutional interventions. Schein (1992) observed three levels in any culture. First level, artefacts, includes observable daily features such as rituals, jargons and similar others. The second level includes values and beliefs. The third level is basic assumptions and it includes deepest and most comprehensive believes of society that sometimes hidden in minds. The third level used to influence general behaviour of people in a social framework (Schein, 1992). People may accept temporary changes in first and/or second levels of culture but ultimately the third level of culture dominates (Argyris \& Donald, 1978; Schein, 1992). The behaviour of people is determined by cultural values embedded in the third level. A longlasting behavioural modification in the third level of culture may be possible through necessary initiatives. However, for sustainability of new behaviour the planned changes in culture should have the ability to satisfy the people through improving their quality of life or economic status.

Improvement of economic status is often effective motivator and satisfier to a person for performing any activity. In this context, behaviour of a person is a function of level of satisfaction or benefits the person receives from any specific activity. Therefore, consequences of cultural changes should be higher level satisfaction and well-being people derive from new behaviour. Hence behaviour is a function of utility and may be expressed as following where $U$ denotes utility and B denotes behaviour.

$B=f(U)$

The Field Theory by Kurt Lewin explained behaviour as the function of personal motivation or characteristics of individual own and the environment (Lewin, 1951). Environment is the cultural and other social norms around the person. Motivation and environment build up human psychological field and it remains static until there is no change in motivation or in environment (Kassarjian, 1973; Weiner, 1980). Therefore, behaviour of a person may be expressed as the following as well where $M$ is motivation and $\mathrm{C}$ is environment.

$B=f(M, C)$

Any behaviour is determined by force behind it. The force (F) is a measure of strength of the motivation and is a function of distance and valence (Weiner, 1980). The distance (D) reflects the difficulty of doing any activity and has inverse relation with force. The valence (V) is a measure of the degree of attractiveness of an activity to a person and it itself a function of tension (T) and utility (U) of an activity. The tension is a measure of strength of need that is active within the person. Hence, it is possible to derive following relationships.

$B=f(F)$

$F=f\left(T_{s} U_{s} \frac{1}{D}\right)$

A combination of all three relationships described above, it is possible to derive a single function of behaviour as given below that is dependent on present behavioural pattern, utility, environment or culture, tension and distance.

$B=f\left(U_{y} M_{y} T_{y} C_{y} \frac{1}{D}\right)$

Analysis of this model of behaviour may provide an explanation of how a social organisation can change culture in a society and thereby can initiate aspiration adaptation. The characteristics of human behaviour in a society are key determinants of aspiration. The awareness building efforts of the NGOs may create tension among people to change behaviour what may be deviant of existing social culture. To direct tension of people to desired behaviour, it should be supported by opportunities. For example, if the social organisations create tension for female education then there must have affordable opportunities for girls to receive education. Thus the reduction of distance or difficulties related to any activity should strengthen tension. Final change of behaviour will be dependent on the utilities people obtain from new activities they perform out of tension generated by social organisations. If utility is higher than previous state, there may be recurrence of new activity and lead to behavioural change and aspiration adaptation. 
There may be conflict between new behaviour and existing behaviour but rationality should lead people to select one that bring higher level of utility or satisfaction to them. Individual's changed behaviour, when deviant of existing culture, may face objections in societies. Effective support of social organisations to followers of new behaviour and ability to prove benefits of new activities may ultimately convince the society and lead to cultural change. The creation of additional utility may or may not be within the ability of social organisations. If culture accepts the activities then it becomes a norm of society and people learn new way of living, new aspiration window comes in operation. New aspiration window because of cultural change encourage aspiration adaptation in the society.

\section{Objective and Hypothesis}

The NGOs are involved to change cultural values in a rural society to create new aspiration window and encourage aspiration adaptation. It is expected that members of NGOs have different value systems than the traditional rural society of Bangladesh. Therefore, the objective of this paper is to evaluate whether the NGOs could make any significant change in value system of their members and thereby had improved standard of living.

The hypothesis of this paper is, "NGO members have higher level of education, better health status, interest in modern healthcare, more women participation in earned employment, more equal distribution of household resources among male and female and more earning compared to non-members in rural areas of Bangladesh".

\section{Data and Methods}

This paper uses primary data collected from a household survey in rural areas of three districts of Bangladesh. Field investigators surveyed total 2400 rural households using a semi-structured questionnaire. Selection of districts was purposive. The selection of households was random based on sample frame prepared with the help of village leaders that listed name of house heads. This survey collected detailed information of all household members. It could gather information of 12856 persons, 50.7 percent were male and 49.3 percent were female. Among the 2400 households, 1200 were members of three highly reputed social sector non-government organisations (NGO) of Bangladesh. Remaining 1200 households were not members of those NGOs. The non-member households represent general culture of society. Comparison of member households with non-member households exposes effectiveness of NGO's in enhancing capability of people and thereby their ability to change culture and aspiration adaptation.

The three NGOs reviewed are the BRAC, Gonoshashthya Kendra (GK) and Centre for Community Development Assistance (CCDA). The BRAC is very famous NGO engaged in rural development, poverty alleviation and health care activities in Bangladesh and some other countries. GK is also a famous NGO at international level and involved in rural development activities. The CCDA is working on community development in rural areas. All of these three NGOs work for poverty alleviation, better healthcare, education and women empowerment. The survey was administered in the villages of Savar of Dhaka district, Narsingdi district and Daudkandi of Comilla district. Saver is the operational area of GK. This area is very near to capital city Dhaka and highly influenced by urbanisation. Narsingdi is the operational area of BRAC and the survey area was very remote with low level of influences of urbanisation. Daudkandi is near to Comilla, a medium size township in Bangladesh. The survey area had good level of influence of urbanisation and not very distant from town. Hence, the study incorporated the distant factors as well.

Data are analysed using appropriate statistical and spreadsheet software. Wherever possible, differences in findings for members of NGOs and non-members of NGOs' are tested statistically using appropriate tests selected from t-test and $\chi^{2}$-test. In case of t-tests, household groups are considered mutually exclusive and statistically independent. The common null hypothesis $\left(\mathrm{H}_{0}\right)$ for tests is "there is difference in findings". The alternative hypothesis $\left(\mathrm{H}_{1}\right)$ is "finding is not different". The significance level for all tests is 95 percent $(\alpha=0.05)$. For decision about hypothesis, $p$-value is the criteria. The null hypothesis is accepted when $p \leq 0.05$. The null hypothesis is rejected in favour of alternative hypothesis when $p \geq 0.05$. 


\section{Findings}

The ability of NGOs or social organisations is analysed on the basis of household income and expenditure levels, health, education and status of women. These are key issues that make difference between societies and cultures.

\section{Income and Level of Poverty}

The comparison of income and expenditure levels may help to evaluate resource generation capabilities of families. Average annual incomes of member and non-member households are Taka 50127 and Taka 54266 respectively. Average income of non-members is higher and it is expected because solvent families often are not interested to become members of NGOs in rural areas. At 5 percent level this income difference is highly significant $(\mathrm{p}=0.00)$. In general the NGO member households have more income poverty compared to non-member households. It indicates that the poor are members of these organisations.

The average incomes of households are compared after grouping them into five percentile groups according to level of incomes. Table 1 shows this comparison. The average income of lowest 20 percent households of NGO members is higher than non-member households are. However, the difference is not statistically significant at 95 percent confidence level. The third 20 percentile households of NOG member households have higher average income that is statistically significant. After 60 percentile, non-member households have statistically significant higher average incomes compared to NGO member households. This evidence shows that NGO member households have almost equal poverty at the bottom levels of income groups. But at the higher levels non-NGO member households are comparatively richer. It points to the fact that NGO members are not poor than non-members are. This is significant contribution of NGOs because they always deal with poorest people of the society.

Table 1: Comparative average annual income of households in rural areas of Bangladesh in local currency

\begin{tabular}{lccc}
\hline \multirow{2}{*}{ Household Group } & \multicolumn{2}{c}{$\begin{array}{c}\text { Average Annual Income Per } \\
\text { Household (Taka) }\end{array}$} & $\begin{array}{c}\text { Statistical Significance of } \\
\text { Differences between Average } \\
\text { Incomes (p value) }\end{array}$ \\
\cline { 2 - 3 } & NGO Members & Non-Members & 0.12 \\
Bottom 20 percent & 15113 & 12867 & 0.22 \\
Next 20 percent & 26976 & 24990 & 0.00 \\
Next 20 percent & 36339 & 35036 & 0.00 \\
Next 20 percent & 50273 & 52039 & 0.01 \\
Top 20 percent & 108951 & 126190 & 0.00 \\
All Groups & 50127 & 54299 & \\
\hline
\end{tabular}

\section{Expenditure levels of households}

In the literature of poverty, the level of expenditure is often considered as better measurement of poverty compared to level of income. Ability to spend is more important yardstick of poverty reduction because more expenditure may enable households to consume more. Data show that non-NGO members and NGO member households have average expenditures of Taka 46,645 and Taka 43,816 respectively. The non member households have higher level of expenditures at 95 percent confidence level $(p=0.00)$. Dividing member and non-member households in five groups like the previous section and comparison between average expenditures of two different groups in all groups shows that expenditure level of two groups are almost similar. The top 20 percent of non-member households have higher level of expenditures and that is statistically significant.

Table 2 presents average annual expenditure of households of two groups. The poverty levels of NGO members and non-member households are almost similar from their capabilities for expenditure. Match between incomes and expenditures of both groups of households indicate the fact that NGOs are showing some success to reduce poverty among people in rural areas of Bangladesh. 
Table 2: Comparative average annual expenditure of households in rural areas of Bangladesh in local currency

\begin{tabular}{lccc}
\hline Household Group & $\begin{array}{c}\text { Average Annual Expenditure Per } \\
\text { Household (Taka) }\end{array}$ & $\begin{array}{c}\text { Statistical Significance of } \\
\text { Differences between Average } \\
\text { Incomes p value }\end{array}$ \\
\cline { 2 - 3 } & NGO Members & Non-Members & 0.10 \\
Bottom 20 percent & 32832 & 36601 & 0.00 \\
Next 20 percent & 30007 & 30891 & 0.53 \\
Next 20 percent & 39149 & 36760 & 0.77 \\
Next 20 percent & 46123 & 46696 & 0.00 \\
Top 20 percent & 70972 & 82387 & 0.00 \\
Total & 43817 & 46645 & \\
\hline
\end{tabular}

\section{Education Levels}

Education is an area where NGOs used to play major role. NGO members are expected to have higher levels of education. However, data from this survey do not support that hypothesis. Average level of education of households of NGO members is 2.43 years, compared to 2.79 years in non-NGO member households. This difference is statistically significant at 95 percent level as calculated p-value of these averages is 0.00 . This fact leads to the opinion that NGO members' households do not have higher level of education compared to non NGO members' households. 38.8 percent people are illiterate in NGO member households. That statistic for non-NGO members is 36.6 percent.

Table 3 shows level of education as aggregate percent of all households. Except primary education, in all other cases non-NGO member households have higher level of educations. Assuming hypothesis that level of education is same between two groups of households and then applying $\chi^{2}$ test, it is observed there is significant difference between two types of households. The calculated $\chi^{2}$ is 31.52 and its $p$ value is 0.00 . Therefore, there is statistically significant difference in educational levels. NGO are apparently not very successful in increasing educational levels in the rural households of Bangladesh.

Table 3: Level of education as percent of total survey population

\begin{tabular}{lccc}
\hline \multirow{2}{*}{ Level of Education } & \multicolumn{2}{c}{ Household Type } & \\
\cline { 2 - 3 } & NGO Member & Non NGO Member & All Household \\
\hline No education & 19.5 & 18.2 & 37.7 \\
Primary education & 20.2 & 19.2 & 39.4 \\
Education up to class eight & 5.6 & 6.5 & 12.1 \\
Secondary education & 3.3 & 4.4 & 7.7 \\
Higher secondary education & 1.0 & 1.2 & 2.2 \\
Graduation and above & 0.4 & 0.5 & 0.9 \\
Total & 50.0 & 50.0 & 100.0 \\
\hline
\end{tabular}

\section{Health Status and Healthcare Uses}

Ability of NGOs or social organisations to improve health status of people and to modify their health seeking behaviour is another measure to judge these organisations as agents of aspiration adaptation. Poor population used to suffer from sickness more than non poor population and they consume healthcare less as well. The poor often prefer locally available traditional medical care to modern medical care because of expenses, limited information on availability of appropriate medical care or superstitions. NGOs should have changed the health seeking behaviour of the poor. Earlier discussion shows that NGO member households are relatively poor and less literate. Hence, higher level of sickness might be normal in NGO member households but improved health seeking behaviour is expected.

Prevalence of sickness is high among NGO member households what is 175 per 1000 population. This rate is 168 per 1000 population in case of non-NGO member households. About 69 percent of NGO 
member households and 63 percent non-NGO member households reported at least one incidence of sickness in their households. People suffered on average 10.92 days and 11.14 days from sickness in NGO households and non-NGO households respectively. The NGO members suffered less because they take healthcare earlier. Average expenditure for healthcare for a person in member households is Tk. 647 compared to Tk. 867 in non-member households. Figure 1 shows expenditures by two groups of households for different components of healthcare. Non-NGO members used to pay more for all components. However, among the three components, the difference of expenses for "other" items is statistically significant $(p=0.004)$. These other items are in general transaction costs and unscheduled payments for getting healthcare at the facilities. The member households have more knowledge about how to get medical care. They can approach healthcare providers easily and they are comparatively prompt to seek healthcare. This is reflection of consciousness NGO member households about their own health what is less visible in case of non-NGO member households.

Figure 1: Comparative expenditure of components of medical care in rural areas of Bangladesh

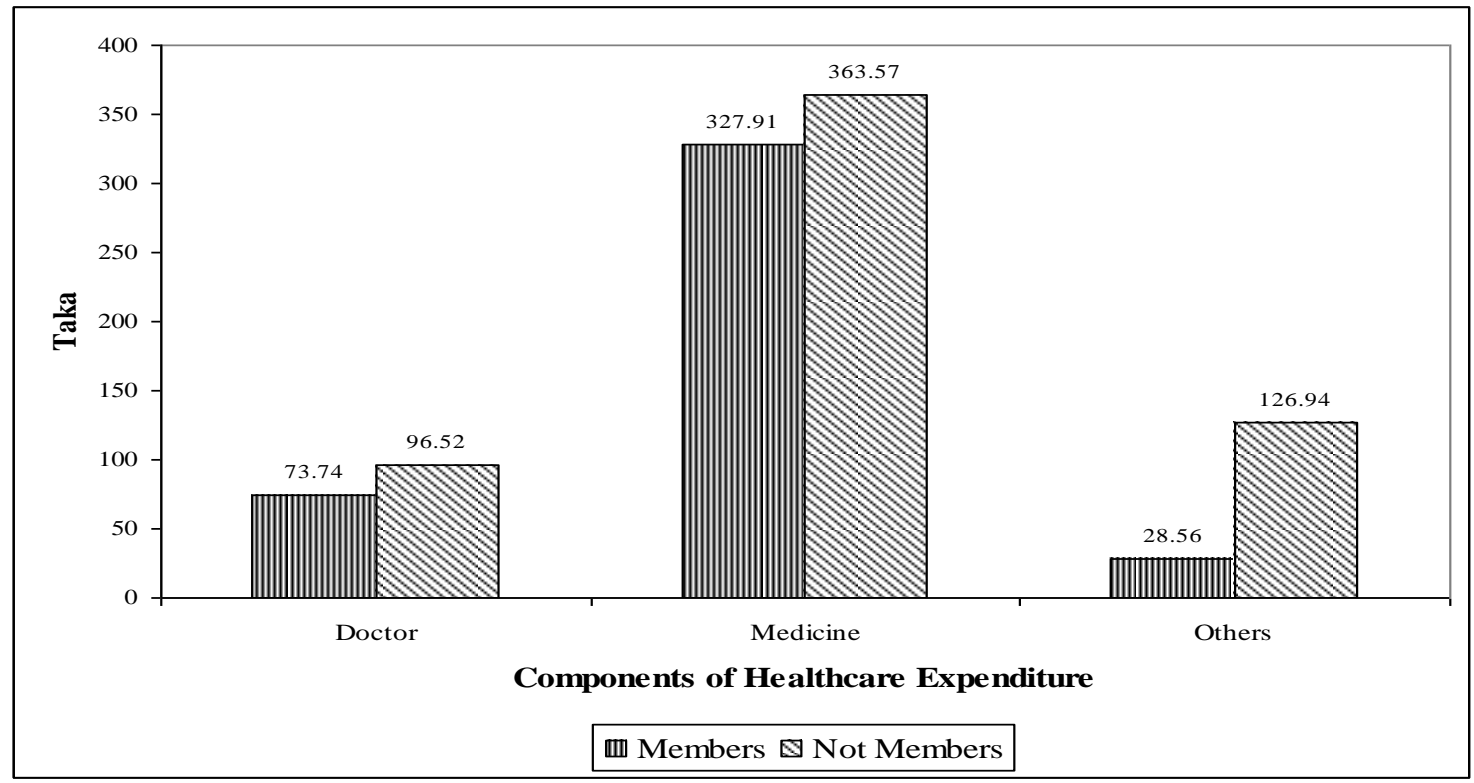

There is difference between two groups of households in seeking healthcare. Table 4 presents sources of medical care of two groups. The NGO member households used to take healthcare more from public sector facilities and NGO clinics. Non NGO member households use private sector and other sources more than the NGO households. NGO member households receive less medical care from unqualified physicians or quacks compared to non-member households. 14.6 percent of non-member sick persons take healthcare from unqualified physicians and quacks compared to 9 percent in case of NGO member persons. Application of $\chi^{2}$ test exposes statistically significant difference in sources of medical care for two groups. The calculated $\chi^{2}$ is 110.930 at 6 degree of freedom and significance level $p=0.000$. Hence, NGO member households are using public sector low cost healthcare facilities more compared to other households and able to keep their healthcare expenses low.

Table 4: Source of medical care for two group of households (percent)

\begin{tabular}{lcc}
\hline \multirow{2}{*}{ Source of Medical Care } & \multicolumn{2}{c}{ Membership status of households } \\
\cline { 2 - 3 } & NGO Member & Not NGO Member \\
\hline Non qualified physicians / quacks & 9.0 & 14.6 \\
Private sector providers & 7.2 & 8.5 \\
Public sector health facilities & 61.0 & 59.4 \\
NGO hospitals / clinics & 8.7 & 0.5 \\
Neighbouring country India & 8.9 & 13.5 \\
Self medication & 2.8 & 2.9 \\
No treatment & 2.5 & 0.7 \\
Total & 100.0 & 100.0 \\
\hline
\end{tabular}




\section{Women Empowerment}

Females face negligence and discrimination in all spheres of society in Bangladesh. The NGOs could work as agents of women empowerment in society, especially in rural areas. However, data of this study do not confirm the NGOs as strong change agents. 3.6 percent of females in member households earn for families compared to 3.2 percent in non-member households. The difference between these two statistics are not statistically significant $(\mathrm{p}=0.404)$. Female in NGO member households almost have similar status as earning member of the household.

\section{Professional Status}

Professional status of women is given in table 5. More women in member households are engaged in farming, business and other employments. 72.4 percent women of non-NGO member households are either unemployed or housewives while that is 71.6 percent in NGO member households. This table cannot be tested statistically for procedural limitations.

Table 5: Profession of women in rural areas of Bangladesh shown in percentage of all women in a group

\begin{tabular}{lcc}
\hline \multirow{2}{*}{ Profession of Women } & \multicolumn{2}{c}{ Household Type } \\
\cline { 2 - 3 } & NGO Member & Not NGO Member \\
\hline Agriculture / Farming & 0.2 & 0.1 \\
Business & 0.7 & 0.3 \\
Employment & 1.6 & 1.2 \\
House wife & 43.7 & 47.9 \\
Student & 25.9 & 26.1 \\
Labourer & 0.6 & 0.4 \\
Unemployed & 27.9 & 24.5 \\
\hline
\end{tabular}

\section{Educational Status}

The status of education of female between member and non-member households is not significantly different. Table 6 presents level of education of women in both groups of households. There is no statistically significant difference in the education status of two groups $\left(\chi^{2}=7.345 ; \mathrm{df}=5 ; \mathrm{p}=0.196\right)$. Very near to 50 percent female are uneducated in both groups. The data shows that NGO could not make any difference in educational status of women.

Table 6: Level of education of women in percentage in rural areas

\begin{tabular}{lcc}
\hline \multirow{2}{*}{ Educational Status of Women } & \multicolumn{2}{c}{ Membership Category } \\
\cline { 2 - 3 } & NGO Member & Not NGO Member \\
\hline No education & 44.8 & 43.2 \\
Primary education & 38.0 & 37.0 \\
Education up to class eight & 11.0 & 12.1 \\
Secondary education & 4.9 & 6.2 \\
Higher secondary education & 1.0 & 1.1 \\
Graduation and above & 0.4 & 0.3 \\
Total & 100.0 & 100.0 \\
\hline
\end{tabular}

\section{Education Earning Relation}

Table 7 shows the relationship between education level of women and their participation in earning activities. It shows that women in NGO member households participate more in earned employment related activities as they move up the educational level. At no education level, slightly more women from non-member households involved in earned employment and excluding this women from NGO member households are more employed in all other groups. 15.4 percent of women of member households who have education at higher secondary level are employed. This statistic is 10.7 percent in non member 
households. This data point to the fact that NGOs might have succeeded to motivate women to be involved more in earned activities. It is especially true in case of educated women. The NGOs have initiated aspiration adaptation among educated rural women.

Table 7: Employment to education level ratio in percent in rural areas

\begin{tabular}{lcc}
\hline \multirow{2}{*}{ Education Level } & \multicolumn{2}{c}{ Household Type } \\
\cline { 2 - 3 } & NGO Member & Not NGO Member \\
\hline No education & 5.1 & 5.7 \\
Primary education & 2.6 & 1.8 \\
Education up to class eight & 4.2 & 1.9 \\
Secondary education & 10.3 & 5.0 \\
Higher secondary education & 15.4 & 10.7 \\
Graduation and above & 9.1 & 25.0 \\
Total & 4.4 & 3.9 \\
\hline
\end{tabular}

\section{Sources of Healthcare}

Analysis shows no difference in healthcare seeking behaviour for male and female in the member households and non-member households. However, medical care obtained by households for females have different patterns in member and non-member households. Figure 2 shows comparative medical care received by two groups of households for women. Non-member households consult unqualified or quacks and private sector physicians more for women than other group. The statistical test $\chi^{2}$ shows significant difference in health seeking behaviour for women between two groups. Calculated $\chi^{2}$ is 55.95 at 95 percent level of confidence and $p=0.00$. The figure shows higher consumption of healthcare by member households compared to non-member households.

\section{Figure 2: Source of medical care for women in rural areas}

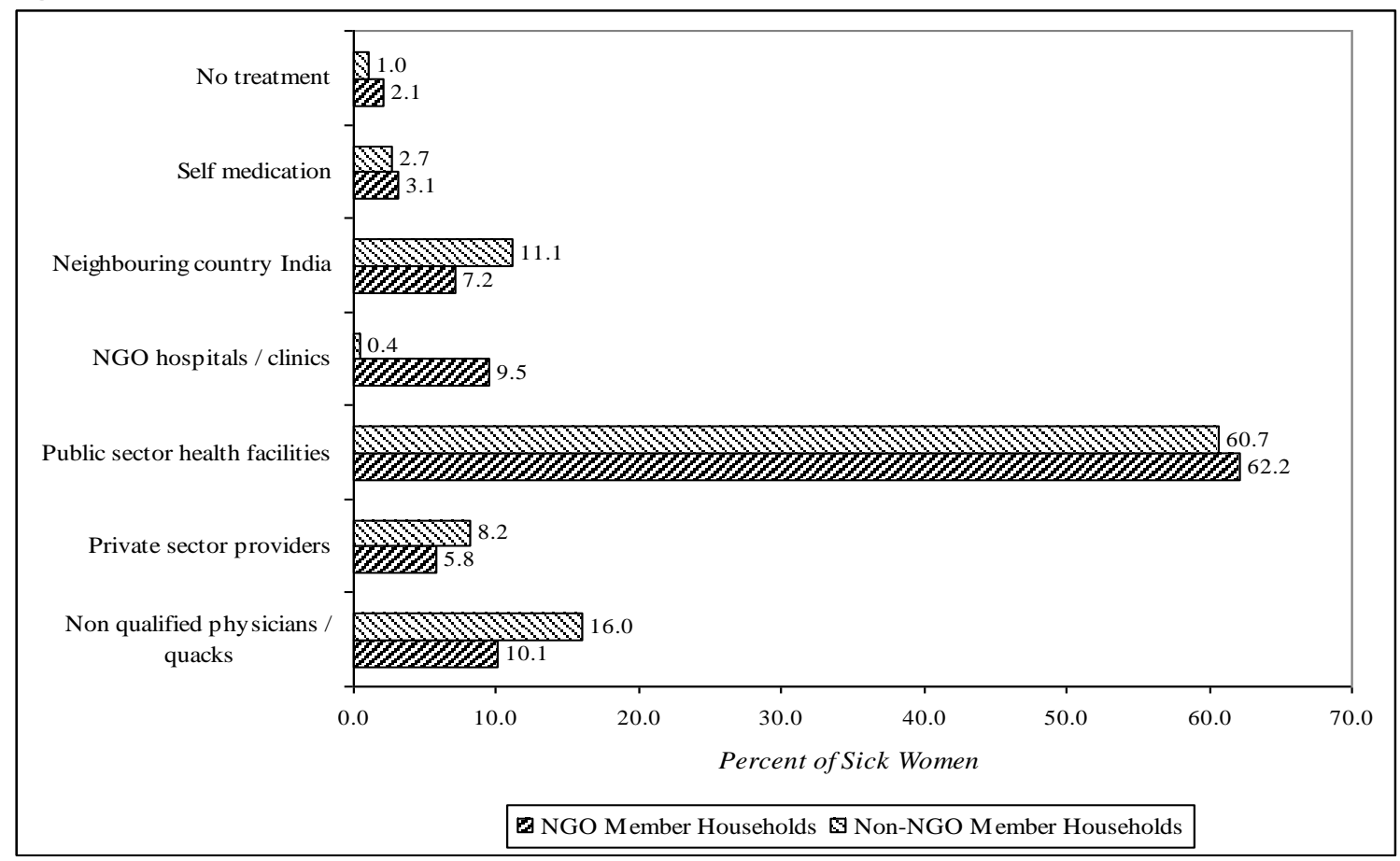

\section{Analysis of Findings}

Cultural change and aspiration adaptation is possible by social organisation but the pace of change may be slow and complex. This paper has analysed activities of NGOs who are working for more than 20 years in rural Bangladesh and observed partial successes of them in changing aspiration windows of people. They have shown success in removing poverty what is an economic effort what needs change in 
aspiration window. However, they made some, though not enough, headway in women empowerment and that is a real change in cultural value structure of rural society of Bangladesh where women live under the practice of female seclusion that is traditionally known as "purdah". They have also shown some success in changing behaviour for seeking healthcare. The NGOs apparently failed in changing attitude to education.

The NGOs are successful in reducing poverty level of the poorest in the rural areas. Findings from data showed that NGO members have average annual incomes at per with non-member households. The member households also have comparable ability in expenditure for living like the non-members. This means member households are not poor than non-member households are. Earlier said, NGO members are often poorest of the poor; it supports the point that social organisations like NGOs can effectively work for reducing poverty impact in a society. Working for earning is a cultural issue because people often try to find work in traditional earning process and neglect many opportunities of earning because those are unknown known to local culture. It means aspiration adaptation essential for adopting new way of earning or finding jobs in new fields. For example, disguised unemployment in farming is common in poor countries like Bangladesh and do not reduce poverty. Taking some people out of their disguised unemployment status and making available new productive work for them in another area may help reducing household poverty. The NGOs often perform activities of this nature in rural areas. This is may be the reason why we can observe similar level of earning and expenditure capabilities among member and non-member households. This is a success of NGOs in changing traditional cultural value system for job and employments in rural areas.

The NGOs could not improve level of education among its members significantly what is generally expected from them. Peoples belongs to non-members households have more education compared to people in member households. More people in former group have higher level of education. It means these organisations could not change traditional cultural preference to working to education at early age when people are poor. It is certainly a failure and has critical implication for poverty removal and socioeconomic development. Amartya Sen's capability approach identified education as one of capability tool for poverty removal. When people show less interest to education, it may reduce their capability significantly. So after creating aspiration window for people and initiating aspiration adaptation, NGOs may cause aspiration failure because of their inability to motivate people for more education. Attitude to take healthcare changed significantly under influence of NGOs. Traditionally, the rural people in Bangladesh do not understand significance of ill health; they initially avoid it and then often consult locally available healthcare providers without looking for modern healthcare available elsewhere especially in public facilities. It creates opportunity for unqualified healthcare providers or quacks to continue their business. Finding of this paper shows that people in member households take less medical care from unqualified healthcare providers than people of non-member households. They also use public healthcare facilities more and face less transaction costs while seeking healthcare. Length of suffering from sickness in these households is also less. This is a change in cultural value system of rural society to medical care. NGOs probably are changing social norms of rural people to healthcare and making society health conscious.

The NGOs showed mixed success in women empowerment. There is no significant difference between number of earning women in member and non-member households. The NGOs could not show significant success to enhance earning capability of women in rural areas that is critical for women empowerment. They could not increase level of education among women but showed success to motivate educated women to be engaged in earned employment. Perhaps traditional norm of society, whatever is the level of education of women ultimately their work would be inside households for family only, is changing under influence of these social organisations. Women receive comparatively better healthcare in member households compared to non-member households. Healthcare is an area where women face highest level of discrimination in rural society of Bangladesh. Social norms under influence of 'purdah' used to deny healthcare needs of women. The NGOs have been changing this view of society gradually; at least findings of this study confirm that conclusion. It is a significant change in cultural value system of society. Therefore, these organisations are strengthening the process of women empowerment slowly through changing cultural values. They are also reducing social deprivation of women. The NGOs or social organisations have abilities to work as agents to change cultural norms of a society to socio-economic issues. They may motivate people to change and using appropriate interventions may modify behavioural patterns. This paper has presented some evidences of changes in cultural value systems under the 
influence of NGOs. Though these successes are marginal not even incremental, yet they are certainly changing culture of the society. The aspiration adaptation is happening under the influence of NGOs.

\section{Conclusion}

The objective of this paper is to analyse the ability of NGOs to initiate aspiration adaptation through behavioural modification. It has analysed this enhancement from perspective of positive changes in cultural values in society that may ultimately enhance capability of the poor and deprived. The argument here is very simple, cultural change may remove undesired practices of society and may restructure behavioural pattern in a way that contribute to socio-economic development of rural households. Then aspiration window alters and aspiration adaptation starts. Findings and analysis support the objective of the paper. Influence of NGOs brought some positive changes in the rural society of Bangladesh that should enhance capability of rural poor in long-run. However, it is also observed that these organisations are not successful in all areas. In spite of failure in education, these organisation changed traditional culture to healthcare and created new aspiration window for women. In conclusion, it can be argued with confidence that effective utilisation of social organisation may make significant behavioural modification for aspiration adaptation. These changes afterwards may enhance capability of the poor in society towards socio-economic development of households and poverty reduction.

\section{References}

Argyris, C, \& Donald, A, S. (1978). Organisational Learning: A Theory of Action Perspective, Reading, MA: Addison Wesley.

Clark, D. A. (2005). The Capability Approach: Its Development, Critiques and Recent Advance. Global Poverty Research Group, GPRG-WPS-032.

Derobert, L., Luchini, S. \& Meschl, M. (2003). Human Nature and the Capability Approach. www.unipv.it/deontica/sen/papers/Teschl_Derobert_Luchini.pdf accessed 12 December 2008.

Goody, J. (1996). The east in the west. Cambridge: Cambridge University Press.

Harrison, L. E. \& Huntington, S. P. (2000). Culture Matters: How Values Shape Human Progress. New York: Basic Books.

Kassarjian, H. H. (1973). Field Theory in Consumer Behavior in Scott Ward and Thomas S Robertson (eds.) Consumer Behavior: Theoretical Sources. Englewood Cliffs, N.J.: Prentice-Hall: 118-140.

Lewin, K. (1951). Field Theory in Social Science. New York: Harper \& Brothers.

North, D. C. (1990). Institutions, institutional change and economic performance: Cambridge: Cambridge University Press.

Obaid, T. A. (2005). Culture Matters to Development: it is the "How" and not the "Why" and "What". Bern, Switzerland: Traverse Lecture.

Rao, V. \& Walton, M. (2004). Culture and Public Action: Relationality, Equality of Agency and Development in V. Rao and M. Walton (eds.), Culture and Public Action, Culture and Public Action. Chicago: Stanford University Press: 3-36.

Ray, D. (2006). Aspiration, Poverty and Economic Change, in Banerjee, A., R. Bénabou and D. Mookherjee (eds). What Have We Learnt About Poverty, Oxford University Press.

Saith, R. (2001). Capabilities: the Concept and its Operationalisation QEH Working Paper Series. Queen Elizabeth House: University of Oxford, No 66.

Schein, E. (2002). Organisational Culture and Leadership, Second Edition. San Francisco: Jossey-Bass.

Selten, R. (1998). Aspiration Adaptation Theory. Journal of Mathematical Psychology, 42(2-3): 191-214.

Sen, A. K. (1985). Commodities and Capabilities. Oxford: Elsevier Science Publishers.

Sen, A. K. (1993). Capability and Well-being in M. C. Nussbaum \& A. K. Sen (eds.) The Quality of Life. Oxford: Clarendon Press: 30-53.

Sen, A. K. (2004). How Does Culture Matter? in V. Rao and M. Walton (eds.) Culture and Public Action, Culture and Public Action. Chicago: Stanford University Press: 37-58.

Sen, A. K. (2005, July). Human Rights and Capabilities, Journal of Human Development and Capabilities, 6(2): 151 - 166.

Throshby, D. (2001). Economics and Culture. Cambridge: Cambridge University Press.

Tylor, E. B. (1974, 1871). Primitive culture: researches into the development of mythology, philosophy, religion, art, and custom. New York: Gordon Press.

UNESCO (2002). Universal Declaration on Cultural Diversity, issued on International Mother Language Day, February 21. 
Weiner, B. (1980). Human Motivation. New York: Holt-Rinehart \& Winston.

World Bank (2006). Bangladesh Economics and Governance of Nongovernmental Organizations in Bangladesh. World Bank South Asian Region, Report No. 35861-BD.

Zohir, S. (2004). NGO Sector in Bangladesh: An Overview, Economic and Political Weekly 39 (36): 41094113. 